University of Nebraska - Lincoln

DigitalCommons@University of Nebraska - Lincoln

Roger Kirby Publications

Research Papers in Physics and Astronomy

November 1989

\title{
The Electrical Noise of Carbon Fibers
}

R.O. Dillon

University of Nebraska - Lincoln

Follow this and additional works at: https://digitalcommons.unl.edu/physics_kirby

Part of the Physics Commons

Dillon, R.O., "The Electrical Noise of Carbon Fibers" (1989). Roger Kirby Publications. 43.

https://digitalcommons.unl.edu/physics_kirby/43

This Article is brought to you for free and open access by the Research Papers in Physics and Astronomy at DigitalCommons@University of Nebraska - Lincoln. It has been accepted for inclusion in Roger Kirby Publications by an authorized administrator of DigitalCommons@University of Nebraska - Lincoln. 


\title{
The electrical noise of carbon fibers
}

\author{
R. O. Dillon \\ Department of Electrical Engineering, University of Nebraska, Lincoln. Nebraska 68588 \\ Roger D. Kirby \\ Behlen Laboratory of Physics, University of Nebraska, Lincoln, Nebraska 68588 \\ 1. E. Spain \\ Department of Physics, Colorado State University, Fort Collins, Colorado 80525
}

(Received 15 May 1989; accepted for publication 12 July 1989)

\begin{abstract}
The low-frequency excess electrical noise has been measured on carbon fibers with a wide range of crystalline perfection and corresponding electrical and mechanical properties. Fibers include those prepared from ex-PAN and ex-pitch polymers, and a catalytic-chemical vapor deposited filament. The extensional (Young's) moduli of these fibers varied from about 220 to $890 \mathrm{GPa}(35-130 \mathrm{Msi})$, while the electrical resistivities varied from about 19 to $1 \mu \Omega \mathrm{m}$. The low-frequency electrical noise of each fiber was found to be proportional to $I^{2}$ and to vary as $1 / f^{\alpha}$, where $f$ is the frequency and $\alpha$ is about 1.15 . The most striking feature of the results was the strong dependence of the normalized noise power on the degree of crystalline perfection.
\end{abstract}

\section{INTRODUCTION}

Carbon fibers are inhomogeneous materials in which the basic building blocks can be thought of as ribbons. Each ribbon consists of a stack of graphene planes (planes of hexagonal carbon with vacancies and vacancy clusters), and the stacking can be random (turbostratic ordering) or regular (graphitic). The ribbons are roughly aligned along the fiber axis, and the mean misorientation angle is an important parameter which controls the extensional (Young's) modulus. The arrangement of the ribbons across the section of the fiber depends critically on the type of fiber and such parameters as the processing conditions. For instance, ex-PAN fibers usually have a random arrangement, ex-pitch fibers a radial, and catalytic-chemical-vapor-deposited (CCVD) filaments a tree-ring one. ${ }^{1}$

This disorder ensures that scattering of electrons is mainly by defects, except in the most perfect fibers. The degree of perfection can be partially controlled by the maximum temperature of heat treatment to which the fibers are subjected. However, graphitization and other measures of lattice perfection indicate that lattice defects can be removed more easily in the order ex-PAN, ex-pitch, CCVD fibers. An extensive account of the preparation, structure, and properties of carbon fibers can be found in Dresselhaus et al.

This paper examines the use of conductivity fluctuations (often referred to as $1 / f$ noise) as a probe of the sample perfection. The earlier work of Conner and Owston ${ }^{2,3}$ had established that $1 / f$ noise was present in the fibers. The present paper examines the fuctuations for a wide range of fibers, and shows that the normalized noise power levels are a strong function of sample perfection.

\section{EXPERIMENTAL TECHNIQUES}

Fibers were chosen with a wide range of properties, as is summarized in Table $\bar{I}$. Ex-Pan fibers had moduli ranging from 220 to $480 \mathrm{GPa}$ (35-70 Msi) for the commercial Celion 3000 and GY-70 types, while a heat-treated experimen- tal one, GY-70 +, had a modulus of $690 \mathrm{GPa}(100 \mathrm{Msi})$. The ex-pitch fibers obtained from AMOCO are designated P-100 (a commercial fiber), P-130X (an experimental fiber), and they had high moduli varying from 690 to $890 \mathrm{GPa}$ (100-130 Msi). Tests were aiso made on a pitch fiber with an original modulus of $170 \mathrm{GPa}$ ( $25 \mathrm{Msi}$ ), which had been annealed to $2800^{\circ} \mathrm{C}$. Its resistivity (Table I) was consistent with a modulus of about $550 \mathrm{GPa}$ ( $80 \mathrm{Msi}$ ). One P-100 fiber

TABLE I. Fiber properties.

\begin{tabular}{|c|c|c|c|}
\hline Fiber type & $\begin{array}{l}\text { Diameter } \\
(\mu \mathrm{m})\end{array}$ & $\begin{array}{c}\text { Young's } \\
\text { modulus } \\
{[G P a \text { (Msi) }]}\end{array}$ & $\begin{array}{c}\text { Electrical } \\
\text { resistivity } \\
(\mu \Omega \mathrm{m})\end{array}$ \\
\hline CELLON-3000 & 7.0 & $\begin{array}{c}220 \\
(35 \mathrm{Msi})\end{array}$ & 19.0 \\
\hline GY $-70^{a}$ & 7.0 & $\begin{array}{c}480 \\
(70 \mathrm{Msi})\end{array}$ & 5.0 \\
\hline $\begin{array}{l}\text { GY }-70+ \\
\text { (annealed } \\
3200^{\circ} \mathrm{C} \text { ) }\end{array}$ & 7.0 & $\begin{array}{c}690 \\
(100 \mathrm{Msi})\end{array}$ & 3.7 \\
\hline $\begin{array}{l}\text { P- } 25^{\circ} \\
\text { (annealed } \\
\left.2800^{\circ} \mathrm{C}\right)\end{array}$ & 9.5 & $\begin{array}{l}\sim 550^{d} \\
(80 \mathrm{Msi})\end{array}$ & 4.2 \\
\hline P. $100^{b}$ & 9.0 & $\begin{array}{c}690 \\
(100 \mathrm{Msi})\end{array}$ & 2.88 \\
\hline$P-130 X^{b}$ & 9.1 & $\begin{array}{c}890 \\
(130 \mathrm{Msi})\end{array}$ & 1.09 \\
\hline P.100B & 8.6 & $\begin{array}{c}690^{\mathrm{d}} \\
(100 \mathrm{Msi})\end{array}$ & 2.40 \\
\hline CCVD & 30.2 & & 0.95 \\
\hline
\end{tabular}

Ex-PAN.

${ }^{b}$ Ex-pitch.

'Ex-pitch, boronated.

Estimated, not measured. 
which had been boronated (P-100B) was tested, since its density of carriers was increased by this process, as shown by Dillon et al. ${ }^{4}$ Finally, one CCVD flament which had been annealed at $2800^{\circ} \mathrm{C}$ was tested. It is emphasized that these fibers have a much wider range of properties than those normally obtained commercially.

The electrical resistivity and electrical noise measurements were made using a standard four probe setup, with two current leads and two voltage leads. The samples were mounted on specially designed printed circuit boards, with contacts between the samples and copper strips on the board being made with silver paint. The separasion of the yoltage contacts ranged between 2 and $5 \mathrm{~mm}$, and all contacts were found to be onmic. A constant current through the sample was maintained using batteries and a series load resistor. The noise voltage across the voltage contacts, after blocking the de voltage with capacitors, was amplified by a home-buit preamplifier (voltage gain 950 ), then by an thaco model 1201 amplifier (typical gain 1000). The output of the Ithaco amplifier was then sent to a $-72 \mathrm{~dB} /$ oct low-pass active filter to remove the high-frequency portions of the noise spectrum. The amplified and filtered noise voltage $W(t)$ was measured at rates ranging from $300 \mathrm{~Hz}$ to $12 \mathrm{kHz}$ using a 12 bit analog-to-digital converter interfaced to a Digital Equipmene Corporation LSI-11 computer. These data were then digitally Fourier transformed to obtain the noise voltage spectrum $V(f)$, from which the noise power spectrum

$$
S_{v}(f)=\left\langle V^{2}(f)\right\rangle / \Delta f
$$

could be calculated. A more detailed discussion of the experimental techniques can be found in the paper by Fagerquist, Kirby, and Pearlstein. ${ }^{5}$ Typically 100 noise power scans were averaged to obtain the resultant noise power spectrum. The noise power spectrum obtained with zero current was subtracted from these spectra in order to eliminate contributions from the associated electronics.

Most spectra were taken using a $300-\mathrm{Hz}$ sampling rate, with a 80-Hz low pass filter to prevent aliasing. Typical noise power spectra for two different currents in a Celion 3000 fiber are shown in Fig. 1. The $1 / f$-like rise at low frequencies is apparent in both spectra, and the rapid falloff above $80 \mathrm{~Hz}$

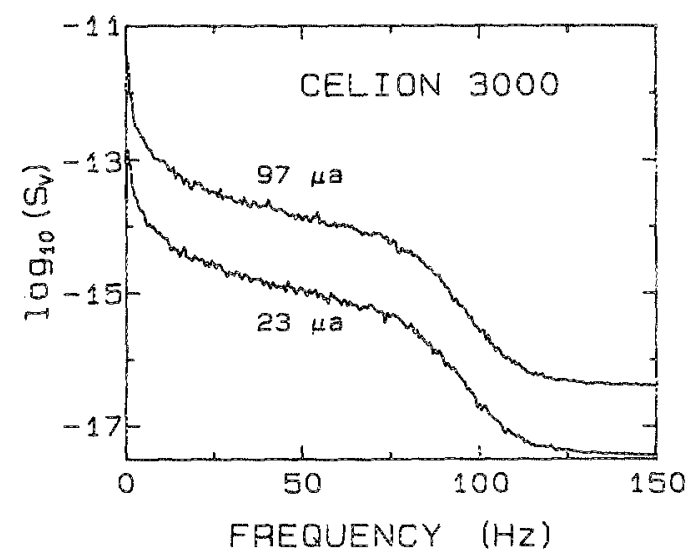

FIG. 1. $\log _{10}$ of the noise power as a function of frequency for two different currents in CELION 3000. is due to the low pass filter. The useful frequency range in these spectra is between 0.6 and $50 \mathrm{~Hz}$, and over this range the magnitudes of the power spectra for each fiber were found to vary as $I^{2}$ in each case. Typical results for the dependence of $S_{v}$ on $Z^{2}$ are shown in Fig. 2 for fiber GY-70+ at a frequency of $10 \mathrm{~Hz}$.

Figures 3 and 4 show the low-frequency behavior of the noise power spectrum for fiber samples GY-70 and P-100B, respectively. The mechanical and electrical properties of these fibers differ considerably, as indicated in Table I. The points in Figs. 3 and 4 are the measured noise powers, while the solid lines are least-squares fits. The slopes $(-\alpha)$ of the fitted curves fall between -1.11 and -1.24 , verifying that these samples indeed show $1 / f$ noise. It should be noted that the P-1003 sample required considerably more current to generate substantial noise than did the GY.70 sample.

\section{DISCUSSION}

Table II summarizes the results of the noise power measurements on the fiber samples. Column 2 of this table gives the values of $a$ for each fiber sample. Note that the $\alpha$ is near 1.15 for all samples, with the estimated experimental uncertainty in $\alpha$ being \pm 0.1 . These values of $\alpha$ are similar to those obtained in carbon resistors by Fleetwood, postel, and Giordano. ${ }^{6}$ Column 3 gives $S_{R}$, the noise power at $1 \mathrm{~Hz}$ multiplied by the sample volume and diviced by the current squared. Use of the phenomenological equation of Hooge, ${ }^{7}$

$$
S_{v}(f)=\gamma\left(V^{2} / N f^{a}\right),
$$

where $\gamma$ is a constant and $N$ is the number of charge carriers in the sampie, together with Ohm's law, shows that this column is proportional to the resistance squared divided by the carrier concentration. Note that $S_{R}$ decreases by about six orders of magnitude on going from the highly defective fibers to the most perfect fibers. While $S_{R}$ is most sensitive to fiber perfection, columns 4 and 5 of Table II provide more fundamental infornation of the source of noise. The quantity $S_{N}$ in column 4 is the noise power times the sample volume divided by the de voltage squared, and is proportional to the inverse of the carrier concentration. Column 5 shows

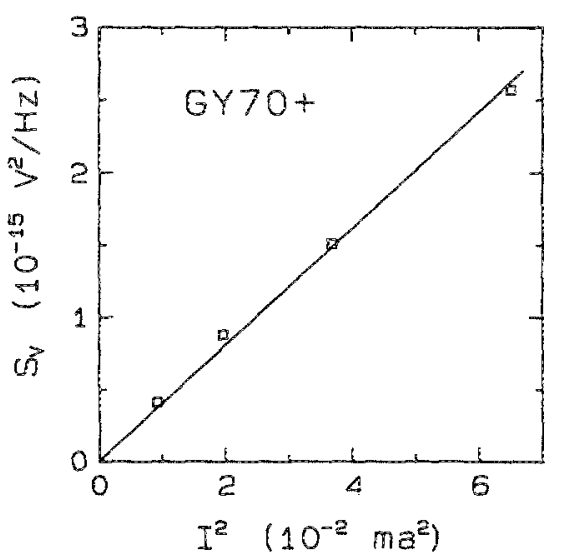

FIG. 2. Noise power vs $I^{2}$ for fiber GY-70+. The points are the measured noise powers, and the solid line is a least-squares fit straight line constrained to pass through the origin. 


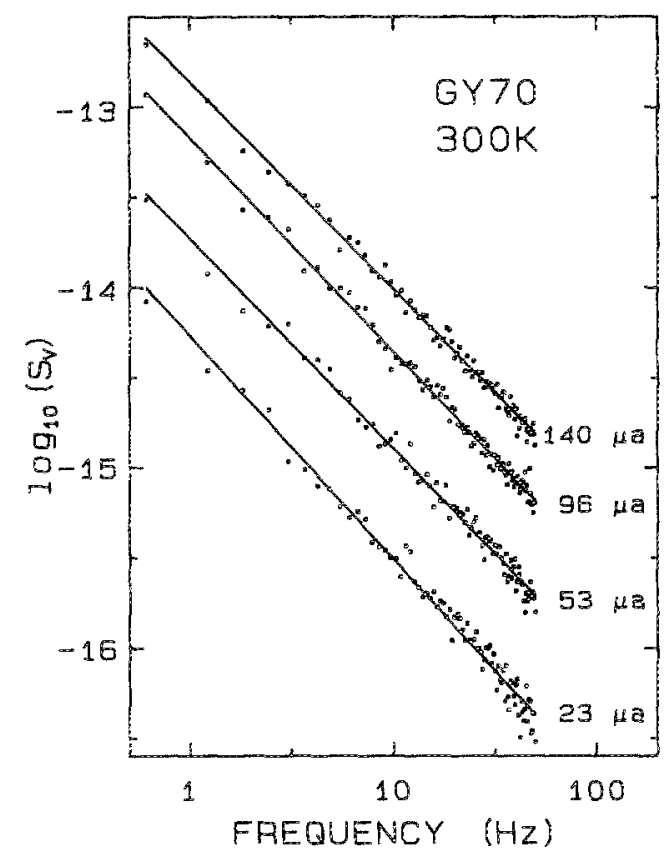

FIG. 3. $\log _{10}$ of the noise power vs $\log _{10}$ of the frequency for fiber GY-70. The points are the measured noise powers, and the solid lines are leasisquares fits to the data. The values of $\alpha$ obtained from these fits range from 1.15 to 1.24 .

$S_{U}$, which is defined as $S_{N}$ divided by the resistance. Since the resistance is inversely proportional to the product of carrier concentration and mobility, $S_{U}$ is proportional to the mobility. The variations of $S_{N}$ in column 4 tend to be greater than those of $S_{U}$, suggesting that the dependence on carrier concentration is more important than that of mobility in comparing the noise of various fibers.

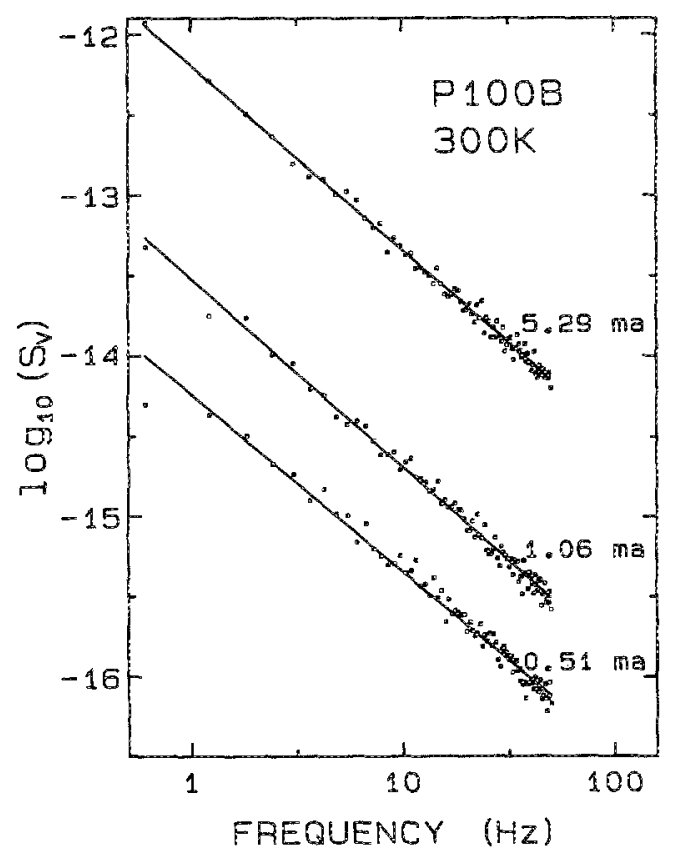

FIG. 4. $\log _{10}$ of the noise power vs $\log _{10}$ of the frequency for fiber $P-100 B$. The points are the measured noise powers, and the solid lines are leastsquares its to the data. The values of $\alpha$ obtained from these fits range from 1.11 to 1.17 .
TABLE II. Noise power results.

\begin{tabular}{ccccc}
\hline $\begin{array}{c}\text { Fiber } \\
\text { type }\end{array}$ & $\alpha$ & $\begin{array}{c}S_{R}(1 \mathrm{~Hz}) \\
\left(10^{18} \mathrm{~V}^{2} \mathrm{~m}^{3} /\right. \\
\left.\mathrm{Hz} \mathrm{A}^{2}\right)\end{array}$ & $\begin{array}{c}S_{N}(1 \mathrm{~Hz}) \\
\left(10^{12} \mathrm{~m}^{3} /\right. \\
\mathrm{Hz})\end{array}$ & $\begin{array}{c}S_{U}(1 \mathrm{~Hz}) \\
\left(10^{30} \mathrm{Am}^{3} /\right. \\
\mathrm{HzV})\end{array}$ \\
\hline CELION-3000 & 1.13 & 18.3 & 14.0 & 1.2 \\
GY-70 & 1.18 & 1.62 & 0.33 & 0.47 \\
GY-70+ & 1.21 & $5.1 \times 10^{-2}$ & 0.12 & 0.58 \\
P-25 & 1.14 & $1.9 \times 10^{-2}$ & 0.051 & 0.26 \\
P-100 & 1.19 & $9.9 \times 10^{-3}$ & 0.069 & 0.56 \\
P-130X & 1.2 & $3.0 \times 10^{-3}$ & 0.091 & 1.7 \\
P-100B & 1.15 & $5.5 \times 10^{-3}$ & 0.030 & 0.22 \\
CCVD & 1.2 & $3.6 \times 10^{-6}$ & 0.021 & 5.1 \\
\hline \hline
\end{tabular}

The origin of $1 / /$ noise in thin metal films and semiconductors has often been assumed to be due to a distribution of carrier activation energies. ${ }^{8}$ Dutta, Dimon, and Horn ${ }^{9}$ used temperature dependence measurements of $1 / f$ noise in thin Ag films to determine the distribution of activation energies, finding that the distribution was peaked near $1 \mathrm{eV}$, with a width of $0.4 \mathrm{eV}$. Fleetwood et al., in their measurements on carbon resistors, also found general agreement with the Dutta-Horn model. ${ }^{8}$ Thus, one may speculate the $1 / f$ noise in carbon fibers may also be appropriately described by a Dutta-Horn-type model which incorporates a distribution of activation energies. We intend to test this idea by carrying out measurements of the temperature dependence of the noise power in a wide range of carbon fibers. Such measurements may result in a more detailed understanding of the carrier-defect interaction in carbon fibers, and it may in fact be possible to distinguish the types and number of defects in fibers prepared by different methods. Further work is also planned in which electrical noise is studied as a function of tensile stress, at stresses near the tensile limit. Such measurements will presumably give valuable information about the fracture mechanisms, which are not well understood at the present time. In particular, it is not understood completely why the tensile strength does not increase with extensional modulus, as predicted by simple models (see for example, the work by Kelly ${ }^{10}$ ), while certain whiskers have both high moduli and strengths. "It is possible that the noise measurements will probe the fracture processes in unique ways.

\section{ACKNOWLEDGMENTS}

Thanks are due to Dr. Imar Kainin of CelaneseHoechst Research Company for donating the ex-PAN fibers. We also wish to thank Dr. John Barr of Amoco Performance Products Inc. for supplying pitch fibers. This research was partially funded by a grant from AFOSR to Colorado State University (Grant No. \$49620-88-C-0017).

'M. S. Dresselhaus, G. Dresselhaus, K. Sugihara, I. L. Spain, and H. A. Goldberg, Graphite Fibers and Filaments (Springer, Berlin, 1988), Vol. 5. ${ }^{2} \mathrm{P}$. C. Connor and J. C. Owston, Nature 223, 1146 (1969). 
${ }^{3}$ J. C. Owston, J. Phys. D 3, 1615 (1970).

${ }^{4}$ R. O. Dillon, T. Kustka, and S. Backhaus, Proceedings of the Nineteenth Biennial Conference on Carbon (American Carbon Society, 1989), p. 262. ${ }^{5}$ R. L. Fagerquist, R. D. Kirby, and E. A. Pearlstein, Phys. Rev. B 39, 5139 (1989).

${ }^{\circ} \mathrm{D}$. M. Feetwood, T. Postel, and N. Giordano, J. Appl. Phys. 56, 3256 (1984).
${ }^{7}$ See, for example, F. N. Hooge, T. G. Kleinpenning, and L. K. Vandamme, Rep. Prog. Phys. 44, 479 (1981).

'P. Dutta and P. M. Horn, Rev. Mod. Phys. 53, 497 (1981).

P. Dutta, P. Dimon, and P. M. Hom, Phys. Rev. Lett. 43, 646 (1979).

${ }^{10}$ A. Kelly, Strong Solids, 3rd ed. (Oxford University Press, Oxford, 1983). ${ }^{n}$ R. Bacon, J. Appl. Phys. 31, 283 (1960). 